\title{
MEDICAL TECHNOLOGY AT HOME: SAFETY-RELATED ITEMS IN TECHNICAL DOCUMENTATION
}

Ellen S.M. Hilbers, Claudette G.J.C.A de Vries, Robert E. Geertsma

RIVM

Objectives: This study aimed to investigate the technical documentation of manufacturers on issues of safe use of their device in a home setting.

Methods: Three categories of equipment were selected: infusion pumps, ventilators, and dialysis systems. Risk analyses, instructions for use, labels, and post market surveillance procedures were requested from manufacturers. Additionally, they were asked to fill out a questionnaire on collection of field experience, on incidents, and training activities.

Results: Specific risks of device operation by lay users in a home setting were incompletely addressed in the risk analyses. A substantial number of user manuals were designed for professionals, rather than for patients or lay carers. Risk analyses and user information often showed incomplete coherence. Post market surveillance was mainly based on passive collection of field experiences. Conclusions: Manufacturers of infusion pumps, ventilators, and dialysis systems pay insufficient attention to the specific risks of use by lay persons in home settings. It is expected that this conclusion is also applicable for other medical equipment for treatment at home. Manufacturers of medical equipment for home use should pay more attention to use errors, lay use and home-specific risks in design, risk analysis, and user information. Field experiences should be collected more actively. Coherence between risk analysis and user information should be improved. Notified bodies should address these aspects in their assessment. User manuals issued by institutions supervising a specific home therapy should be drawn up in consultation with the manufacturer.

Keywords: Home care, Infusion pumps, Ventilators, Dialysis systems, Patient safety

Advanced medical technologies are used in home settings to an increasing extent and this trend is expected to continue in the near future (1-3). Advantages are reduction of costs by shortening hospital stay, as well as improvement of quality of life for patients. However, home use of complex medical devices also brings new specific risks:

Although intermittently supported by healthcare professionals, the patient, and lay carers have to operate the complex equipment themselves to a lesser or larger extent. Despite training provided, they have less medical and technical expertise and experience. Even home care professionals do not always have the opportunity to develop sufficient skills with all devices they may come across in daily practice. This may cause errors in operating complex devices, and inadequate dealing with alarms or unexpected situations. Pets and children, temperature and humidity extremes, dirt and dust, poor lightning, and limited space may interfere with safe and adequate device operation. Risks may also arise from changes in physical and cognitive capacities and emotional stability of patients and caregivers during the treatment period. Additionally, problems may be caused by improper storage, cleaning, maintenance, and calibration. There is no continuous observation of the patient and, therefore, technical defects or medical problems may not be identified immediately and cannot always be solved as promptly

This investigation has been performed by order and for the account of the Health Care Inspectorate of the Netherlands, within the framework of project V/360050 Supporting the Health Care Inspectorate on Medical Technology. as in an intramural setting $(1 ; 4 ; 5)$. Problems with medical devices in home settings have indeed been reported over the past years (6-11). Risk analyses (RA) and instructions for use (IFU) for such devices should be adapted to the abovementioned, often use related, risks.

Manufacturers of medical devices are obliged to perform a risk analysis, reduce risks as far as possible and provide clear instructions for use for their products, taking account of the training and knowledge level of the potential users (12). The European standard on application of risk management to medical devices (7) states: "The manufacturer shall establish, document, and maintain throughout the life-cycle an ongoing process for identifying hazards associated with a medical device, estimating and evaluating the associated risks, controlling these risks, and monitoring the effectiveness of the controls."

Risks that cannot be eliminated by inherently safe design or construction, or reduced by adequate protection measures including alarms, are "residual risks" (RRs). Risks indicated in the RA as residual risks should be addressed on the label and/or in the IFU as warnings, precautions, or contraindications (WPCs), to ensure that the user is properly informed about these risks, and about how they can avoid hazardous situations by taking appropriate measures. On the other hand, all the WPCs that are mentioned in the IFU should originate from the RA as residual risks (13). Mutual coherence between RA and IFU is the extent to which residual risks in the RA and WPCs in the IFU are cross-referenced.

The Medical Devices Directive (12) requires the device manufacturer to have "a systematic procedure to review 
experience gained from devices in the postproduction phase" and to take appropriate measures. This is called post market surveillance (PMS). PMS activities imply the systematic collection, analysis and interpretation of experiences with medical devices.

A crucial aspect of PMS is gathering experiences by means of an active approach, including active customer feedback, post market clinical follow-up (where applicable) and literature reviews, in addition to handling of passive customer feedback, that is, complaints.

Results of these activities have to be analyzed, and if relevant, changes should be made to the risk analysis, design, and/or IFU. This way a continuous cycle of improvement is maintained (14).

In home treatment of patients with advanced technologies, many parties are involved, including industry, government agencies, health practitioners, lay carers, patients, and insurance companies. Acknowledgement of the risks by all the parties concerned, and adequate communication between all parties in the chain of care will enhance patient safety, as does the implementation of proper preventive measures. The Food and Drug Administration (FDA) has recently taken initiatives supporting patient safety in this setting (15).

The Dutch National Institute for Public Health and the Environment (RIVM), an independent government institute for research and policy support, performed studies on safety-related aspects in technical documentation of manufacturers of medical equipment used in a home setting $(6 ; 10 ; 11 ; 16)$. An integrated survey of these studies is presented here.

\section{OBJECTIVES}

The studies aimed to investigate whether manufacturers sufficiently consider and support the safe use of their device by lay users in home settings.

Investigations were focused on four issues: (i) Are risk analyses and instructions for use adequately adapted to home use of the device? (ii) Is there mutual coherence between risk analyses and user information? (iii) Are the procedures for post market surveillance addressing an active collection of field experiences in the postproduction phase? (iv) Are instruction and training facilities offered by the manufacturer?

\section{METHODS}

We selected three categories of equipment: infusion pumps (2006), ventilators (2007), and devices for hemo- or peritoneal dialysis (2008). Reason for the selection of these technologies was that they were examples of techniques showing the combination of an increase in home use, existing reports of incidents, and a potentially high risk for patients.

For each technology, we selected several devices. Only devices that were marketed in the Netherlands were included. From these devices, we made a selection so as to include the different manufacturers on the Dutch market and to cover the different technical and therapeutic characteristics of the devices. The studies comprised nineteen infusion pumps, eight ventilators, and seven dialysis systems (three hemodialysis systems and four peritoneal dialysis systems).

Although we included only a limited number of devices, these represented the majority of the home care ventilators and home dialysis systems used in the Netherlands, and an important part of the infusion pumps for home use. In 2009, we made the comparative assessment for the three categories (16).

We requested technical documentation from the manufacturer for the selected devices. This documentation included the risk analyses, instructions for use, labels, and post market surveillance procedures. Additionally we sent a questionnaire on three issues: collection of field experiences, incidents reported to the manufacturer and training activities. We did not test or investigate the devices themselves.

For the purpose of assessment of risk analyses we compiled an overview of the risks involved in the three technologies from literature, the FDA MAUDE database representing reports of adverse events involving medical devices used in public, private, and nonprofit hospitals (http://www.accessdata.fda.gov/ scripts/cdrh/cfdocs/cfMAUDE/search.cfm) and discussions with experts.

We arranged these risks in six categories which were identical for the three technologies: (i) Assembly and installation of the device and accessories; (ii) Operating the device; (iii) Programming the device; (iv) Technical defects; (v) Risk factors in the home setting; and (vi) Controls, cleaning, maintenance.

During the assessment we scored the percentage of the identified risks that were addressed for each category (see Figure 1). Because some risk analyses for the ventilators and dialysis systems were not submitted, 95 percent confidence intervals (likelihood based confidence intervals) were calculated for these results (17).

For the purpose of assessment of manuals, we listed layout features and relevant content issues. When manuals were available in Dutch, these were evaluated. Otherwise manuals in English were assessed. We arranged the features and issues in four categories which were identical for the three technologies: (i) Layout and clarity of the manual; (ii) Set-up and operating the device; (iii) Dealing with alarms, problems and technical defects; (iv) Cleaning and maintenance.

During the assessment, we scored for each category the percentage of the identified features that were present and of the identified issues that were addressed.

All documents were assessed by two investigators, independently from each other. As assessors may subject the technical documentation to different interpretations, we drew up a guidance document to facilitate objective and consistent assessments. For each device, the two assessments were compared, and inconsistencies were checked and resolved. 


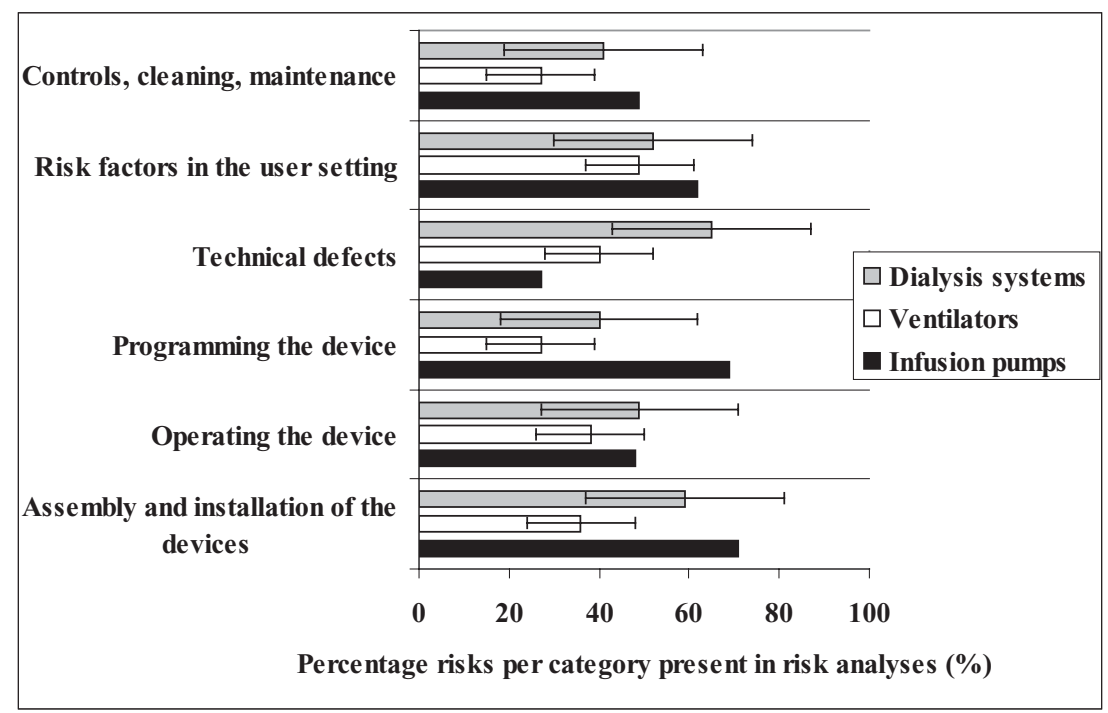

Figure 1. Percentage of the specific risks evaluated per category in the risk analyses. For ventilators and dialysis systems not all risk analyses were submitted. Therefore, for these devices a 95 percent likelihood based confidence interval is presented.

A full description of the assessment is available in the RIVM-report (16).

\section{RESULTS}

All companies replied to our request. However, in some cases $(3 \times$ infusion pump, $0 \times$ ventilator, $2 \times$ dialysis systems $)$ the required documentation was not submitted because the device was no longer on the market, or was not actually used in home settings in the Netherlands.

The assessment of the documentation revealed shortcomings in risk analyses, in user information, in the coherence between risk analyses and user information, and in post market surveillance procedures.

\section{Risk Analyses}

The results of the assessments are summarized for each technology in Figure 1 as a percentage of the identified risks evaluated in the risk analyses. For ventilators and dialysis systems, not all risk analyses were submitted. Therefore, for these devices a 95 percent likelihood based confidence interval is presented.

Faults in the assembly of the infusion pumps, ventilators, and dialyses systems, such as making wrong connections, were addressed in, on average, 71 percent, 36 percent, and 59 percent of the cases, respectively. Only nearly half of the specified risks during the actual use of the device, such as detachment of components or inadequate interventions upon alarm signals, were mentioned: 48 percent, 38 percent, and 49 percent on average. Moreover, risk mitigating actions were sometimes formulated in nonspecific phrases such as "good operators manual."

Possible errors in programming, for example, data entry or interpretation of displays, were mentioned in, on average, 69 percent, 27 percent, and 40 percent of the cases, respectively. It was notable that regulation of alarm limits and alarm volume was hardly ever mentioned.

"Technical defects" in general were mentioned in all risk analyses, but specific problems, such as defective displays or failing alarm functions, were often lacking, resulting in scores of: 65 percent, 55 percent, and 52 percent on average.

Specific risks of home settings, like disruption by children and pets or mobile use, are evaluated in an average of 62 percent, 49 percent, and 52 percent for the three technologies. The risks of installation of ventilators on wheel chairs were hardly ever mentioned.

Issues of cleaning, controls and maintenance were addressed for an average of 49 percent, 26 percent, and 41 percent of the cases, respectively. Cleaning aspects were mentioned often in risk analyses. Procedures for control and maintenance were lacking regularly.

Overall the scores of ventilators were somewhat lower than the results for infusion pumps and dialysis systems.

\section{User Information}

For complex devices the manuals were often voluminous. In these cases, sometimes a condensed manual was supplied in addition, and these were assessed as well. The results of the assessment are summarized in Figure 2 as a percentage of the identified features that were present and of the percentage of the necessary issues which were addressed in the user information of the devices.

The lay out aspects included clear phrasing, correct translation, character size, and convenient arrangement. User manuals were often comprehensive and well-illustrated, but some documents were less understandable because of poor phrasing or incorrect translations from English into Dutch. Four manuals of infusion pumps were not in the national language. A substantial 


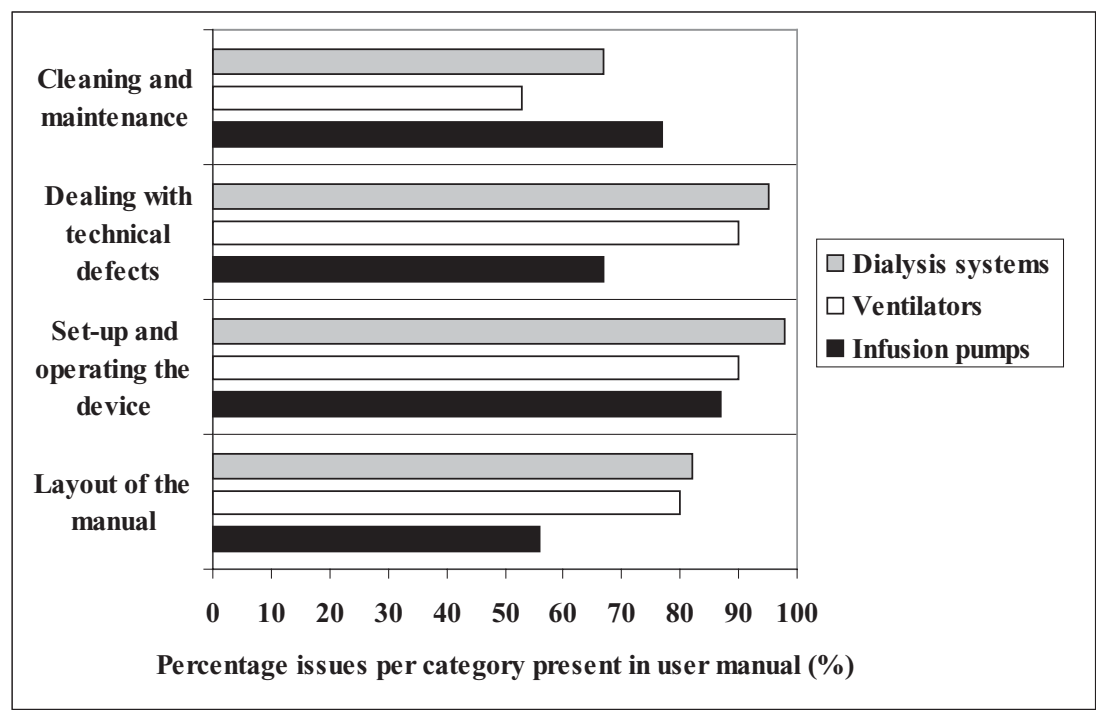

Figure 2. Percentage of specific issues per category addressed in the user manuals

number was designed for professionals, rather than adapted for home use by patients or lay carers.

\section{Coherence Between Risk Analyses and User Information}

Risk analyses frequently stated that residual risks are addressed in the user information. However, in this aspect risk analyses and user information did often show incomplete coherence. As is shown in Figure 3, in many cases not all residual risks were mentioned in the instructions for use.

After we finalized the study on infusion pumps, we found in other studies that, vice versa, warnings, precautions, and contraindications in the user information have not always been evaluated in the risk analysis $(18 ; 19)$. Therefore, in the subsequent studies for ventilators and dialysis systems, the technical documentation sets were also assessed on this aspect. The documentation of the infusion pumps could not be reassessed on this aspect because, according to the agreement with manufacturers, their confidential documents were destructed after finalizing the study. Our results proved that warnings in the instructions for use of ventilators and dialysis systems had not always been evaluated in the risk analysis.

In some cases, the risk analyses were not submitted by the manufacturers, and, therefore, the coherence could not be assessed.

\section{Postmarket Surveillance/Vigilance Procedures}

The postmarket surveillance/vigilance procedures mainly mentioned passive collection of field experiences, by means of recording submitted complaints and device problems. Active ways of collecting user and patient experiences (like user surveys and customer satisfaction studies) were mentioned only a few times. However, according to the answers on the questionnaire all respondents did also actively collect user experiences.
In the procedures, there was insufficient attention for follow-up of findings in terms of, for example, product improvement or other corrective and preventive actions to be taken. Furthermore, the role of distributors was not always specified in the procedures.

\section{Instruction and Training}

From the questionnaires, it appeared that all respondents offered training for their devices. This was mainly meant for the professional caregivers involved, like specialized nurses and technical staff members. In less than half of the questionnaires, namely 45 percent for infusion pumps and 25 percent for ventilators and dialysis systems, training was reported to be given directly to patients and lay caregivers.

\section{DISCUSSION AND CONCLUSIONS}

The technologies selected for these studies are examples of techniques showing an increase in home use, existing reports of incidents, and a potentially high risk for patients. Such advanced and complex medical technologies were traditionally developed for "high tech" professional environments like certain hospital departments. For various reasons, long-term medical treatments are shifting to home settings more and more, even when complex equipment is involved. The spreading of technology to new "low tech" environments adds new and specific risks. This is reflected in incidents occurring not only in hospital, but also at home.

To minimize risks of use of medical devices, the manufacturer should identify all known or foreseeable hazards in a risk analysis as part of his risk management procedure. According to the European standard on application of risk management to medical devices, all risks arising from the identified hazards should be estimated, actions must be taken to eliminate or reduce the risks, and these actions should be clearly described 


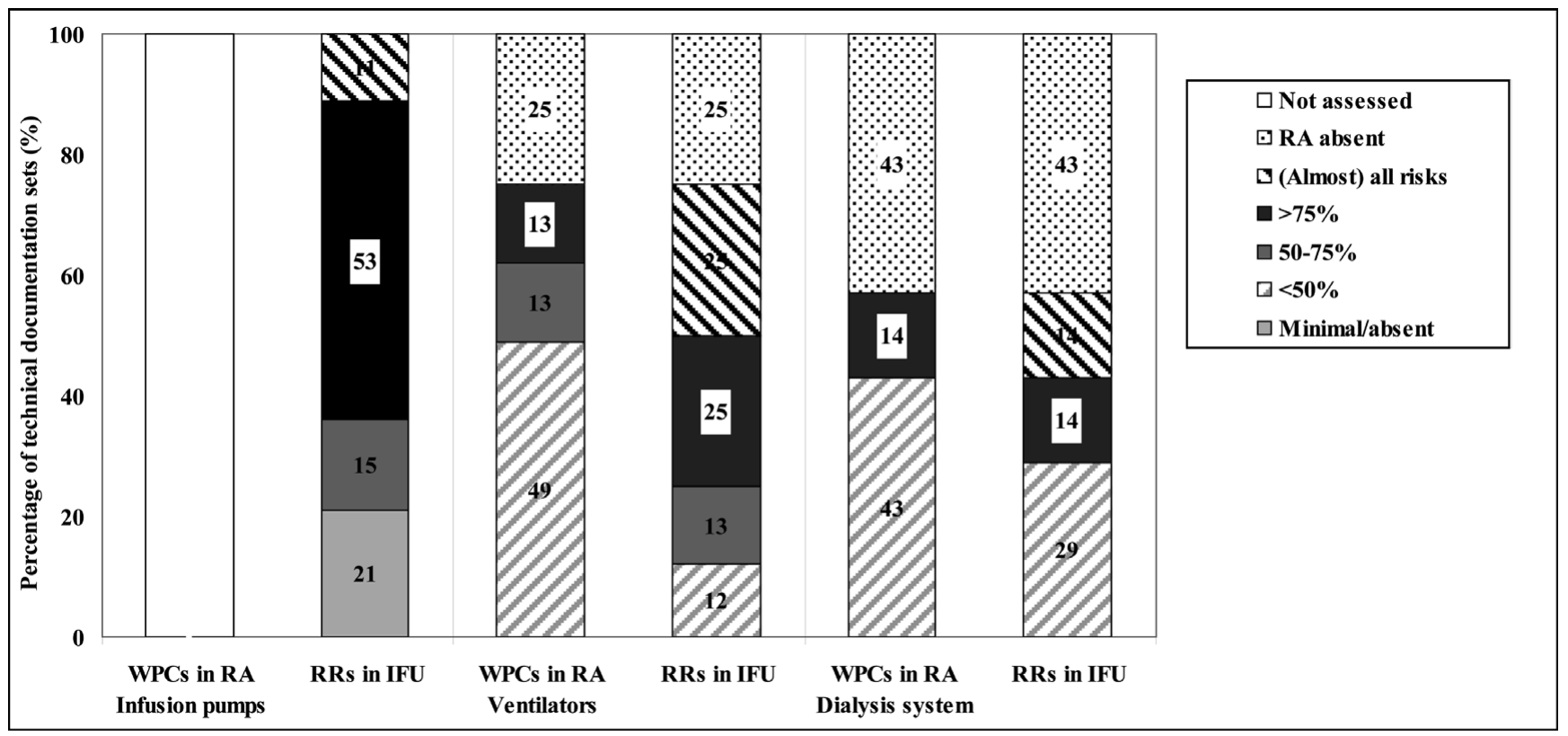

Figure 3. Coherence between residual risks (RRs) in risk analyses (RA) and warnings, precautions and contraindications (WPCs) in user information (IFU). The columns WPCs in RA represent the percentage of technical documentation sets in which WPC's mentioned in the IFU are found in the RA as RRs. The columns RRs in IFU represent the percentage of technical documentation sets in which RRs mentioned in the RA are found in the IFU as WPCS. Note. After we finalized the study on infusion pumps, where only RRs in IFU were evaluated, we found in other studies that vice versa WPCs in the IFU have not always been evaluated in the RA. Therefore, in the subsequent studies for ventilators and dialysis systems, the technical documentation sets were also assessed on this aspect. The documentation of the infusion pumps could not be reassessed on this aspect because, according to the agreement with manufacturers, their confidential documents were destructed after finalizing the study.

and proven to be adequate (7). This study revealed that user faults, specific hazards in a home setting, and device operation by lay users were not always sufficiently addressed in the risk analyses and moreover, risk mitigating actions were sometimes formulated in nonspecific phrases.

A notable finding was that the adjustment of alarm limits and alarm volume was hardly ever mentioned. However, alarm hazards rank highly - the second place — on the recent top 10 list of health technology hazards (20). In the home setting, a low alarm volume may cause serious or fatal incidents when noise from, for example, vacuum cleaner, etc., prevents the notice of an alarm by caregivers, or when sleeping caregivers are not awakened by the alarm (8).

Another remarkable finding was that the risks of installation of ventilators on motorized wheel chairs were hardly ever mentioned. Such installation may have consequences for power supply, weight, stability, solidity, and moisture resistance. The Dutch Health Care Inspection found that 75 percent of the patients concerned had experienced hazardous events using ventilators on a wheelchair (21). A fire incident for a ventilator on a wheelchair was reported recently (9).

For risk analyses, overall scores of ventilators were somewhat lower than the results for infusion pumps and dialysis systems. This is cause for concern, particularly because these devices are often "life supporting", and problems have to be solved within minutes.

User manuals were often comprehensive and wellillustrated, but a substantial number was designed for professionals, rather than adapted for home use by patients or lay carers. In recent years, the FDA developed educational tools for the public (like a brochure on infusion therapy, advices for infusion pump risk reduction for patients and home health nurses, and a home medical device checklist) and intends to develop guidance recommending manufacturers to perform pre market device-usability tests with at-home caregivers and patients in a nonclinical setting. These initiatives are now embedded in the Medical Device Home Use Initiative (15).

When a risk cannot be reduced to an acceptable level by elimination, reduction, and/or protective measures, the user must be informed of the residual risks (7). The residual risks should be addressed on the label and in the instructions for use as warnings, precautions, or contraindications, to ensure that the user is properly informed about these risks and about how they can avoid hazardous situations by taking appropriate measures. Residual risks were often not all mentioned in the instructions for use. Vice versa, warnings in the instructions for use had not always been evaluated in the risk analysis. This finding is not unique for medical devices for home use (13). It suggests that coherence between risk analyses and instructions for use is incomplete, which raises questions about the thoroughness of the risk mitigation procedure followed by the manufacturers of the medical devices and the accuracy of the communication of the residual risks to the user.

Manufacturers must keep up to date a systematic procedure to review experience gained from devices in the postproduction phase and to implement appropriate means to apply any necessary corrective action (12). Gathering field experiences for post market surveillance may include several strategies in addition 
to passive complaint handling, like active supervision by customer surveys and inquiries of users and patients (7). From the procedures submitted for this study, it appeared that postmarket surveillance was mainly based on passive collection of field experiences, like complaint handling, only to a limited extent supplemented with methods of active collection of field experiences. Furthermore, the procedures did not show sufficient implementation of appropriate means to apply any necessary corrective actions. These aspects should be key elements of the procedures, in order to achieve a better functioning "continuous cycle of improvement" (14).

The Dutch Health Care Inspectorate concluded in 2004 that problems and incidents with medical devices in a home setting are reported incompletely (22). FDA addresses this aspect by encouraging patients and nurses to report problems with medical devices in the home setting to HomeNet, a subnetwork of MedSun (23).

All respondents offered user training for their devices, mainly for the professional caregivers involved, only partly directly for patients and lay caregivers. The latter are mostly trained by the professionals in turn. In the Netherlands the instruction for dialysis and ventilation at home is given principally by specialized centers supporting and supervising these therapies. Training lay users for infusion therapy is performed by the hospital and/or institution for medical homecare.

The general conclusion is that manufacturers of infusion pumps, ventilators, and dialysis systems do not pay sufficient attention to the specific risks of use by lay persons in home settings. As a consequence, patient safety could be compromised. In the Netherlands, those institutions and hospitals that supervise medical home treatment do often take adequate measures to counterbalance these shortcomings appropriately. This may be by personal instruction and training, counseling, and provision of additional, condensed manuals. However, this does not mean that manufacturers can afford to neglect the need for adaptation of their instructions for use to lay users in a home environment.

The results found for the three categories of home use medical devices that were investigated lead to similar conclusions. Studies on other medical technologies used in various settings yielded comparable findings: shortcomings in adapting risk analysis and user manual to the intended user and setting $(13 ; 18 ; 19 ; 24 ; 25)$. Therefore, it can be expected that shortcomings are also present in risk analyses and user manuals of other medical home care technologies. This does not necessarily mean that quality and safety of the devices are insufficient. However, when the risk analysis is incomplete, when warnings and precautions are lacking in the manual and on the label, or when field experiences are not used optimally to improve the product, this means that the product safety and the provisions for the safe use of the device are not fully present. It follows subsequently that conditions for patient safety are not as optimal as possible.

\section{RECOMMENDATIONS}

It is recommended that manufacturers of medical equipment for home use pay more attention to user faults, use by lay persons and home specific risk factors in design, risk analysis, and user information. Manufacturers should collect field experiences more actively, use these experiences for product improvement and secure the coherence between risk analysis and user information. Notified bodies, who are involved in the certification of these products for market access in Europe, should monitor whether manufacturers have addressed the abovementioned aspects. If additional user manuals are issued by institutions that support and supervise a specific therapy, these should be drawn up in cooperation with the manufacturer of the device.

\section{CONTACT INFORMATION}

Ellen S.M. Hilbers, PhD, (ellen.hilbers@rivm.nl), Claudette G.J.C.A de Vries, MSc, and Robert E. Geertsma, MSc, RIVM, P.O. Box 1, NL 3720BA Bilthoven, The Netherlands

\section{CONFLIC OF INTEREST}

The authors report payment to their institution for this work from the Health Care Inspectorate of the Netherlands, within the framework of project V/360050 supporting the Health Care Inspectorate on Medical Technology.

\section{REFERENCES}

1. Hollestelle ML, Hilbers ESM, van Tienhoven EAE, Geertsma RE. Geavanceerde medische technologie in de thuissituatie - Inventarisatie, gebruikersaantallen en risico's. Dutch. Bilthoven: National Institute for Public Health and the Environment; 2005. [cited 2012 May 8]. Available from: http://www.rivm.nl/bibliotheek/rapporten/265011004.pdf.

2. National Association for Home Care \& Hospice. Basic statistics about home care - Updated 2010 - Draft, NAHC; 2010. [cited 2012 May 8]. Available from: http://www.nahc.org/facts/10HC_Stats.pdf.

3. Schermer M, van Kammen J. Advanced Home Care Technology: Moral Issues Surrounding a New Healthcare Practice. Zoetermeer: Council of Public Health and Healthcare - Centre for Ethics and Health; 2004.

4. Bitterman N. Design of medical devices-a home perspective. Eur J Intern Med. 2011;22:39-42.

5. FDA. Unique Considerations in the Home. 2010. [cited 2011 May 19]. Available from: http://www.fda.gov/MedicalDevices/Productsand MedicalProcedures/HomeHealthandConsumer/HomeUseDevices/ ucm204452.htm.

6. Drongelen AW van, Hilbers ESM. Zijn de risico's van apparatuur voor thuisbeademing door fabrikanten voldoende afgedekt? Dutch. Bilthoven: National Institute for Public Health and the Environment; 2007 [cited 2012 May 8]. Available from: http://www.rivm.nl/bibliotheek/ rapporten/360050005.pdf.

7. EN ISO 14971: 2009. Medical devices - Application of risk management to medical devices. CEN/CENELEC, Brussels, 2009. [cited year Month, day]. Available from: www.cen.eu/CEN/Sectors/Technical CommitteesWorkshops/CENTechnicalCommittees/Pages/Standards. aspx ?param $=581003 \&$ title $=\mathrm{CEN} / \mathrm{CLC} / \mathrm{TC}+3$.

8. ECRI. A Lifesaving reminder: improper use of ventilator alarms places patients at risk. Health Devices. 2009;38:124-5. 
9. FDA. Case Study for February: Hot Seat. 2011. [cited 2011 May 19]. Available from: http://www.fda.gov/MedicalDevices/Productsand MedicalProcedures/HomeHealthandConsumer/HomeUseDevices/ ucm238841.htm.

10. Hollestelle ML, de Bruijn ACP, Hilbers-Modderman ESM. Infuuspompen in de thuissituatie. Dutch. Bilthoven: National Institute for Public Health and the Environment; 2006. [cited 2012 May 8]. Available from: http://www.rivm.nl/bibliotheek/rapporten/360050015.pdf.

11. de Vries CGJCA, Hilbers ESM, de Bruijn ACP. Zijn de risico's van de apparatuur voor thuisdialyse door de fabrikanten voldoende afgedekt? Dutch. Bilthoven: National Institute for Public Health and the Environment; 2008. [cited year Month, day]. Available from: http://www. rivm.nl/bibliotheek/rapporten/360050016.pdf.

12. European Commission EC. Council Directive 93/42/EEC of 14 June 1993 concerning medical devices, as amended by Directive 2007/47/EC of the European Parliament and of the Council of 5 September 2007. [cited year Month, day]. Available from: http://eur-lex.europa.eu/ LexUriServ/LexUriServ.do?uri=CONSLEG:1993L0042:20071011:en: PDF.

13. de Bruijn ACP, van Drongelen AW, Hilbers ESM, et al. Coherence between risk analysis and instructions for use. Regul Aff Medtech. 2011;March/April:8-9. [cited year Month, day]. Available from: http:// www.rajpharma.com/productsector/medicaldevices/Coherencebetween-risk-analysis-and-instructions-for-use-in-the-EU-312531.

14. van Drongelen AW, Roszek B, Kraus J, Geertsma R. Assessing how widespread the continuous cycle of improvement of medical devices is in the EU. Regul Aff Medtech. 2011;July/August:20-22.

15. FDA HUI. Medical Device Home Use Initiative. [cited 2012 May 8]. Available from: http://www.fda.gov/downloads/MedicalDevices/ ProductsandMedicalProcedures/HomeHealthandConsumer/HomeUse Devices/UCM209056.pdf.\%20C.\%20f.\%20D.\%20a.\%20R.\%20Health \%20and\%20U.\%20S.\%20F.\%20a.\%20D.\%20Administration.

16. Hilbers ESM, de Vries CGJCA, Geertsma RE. Veiligheid van medische technologie in de thuissituatie. Dutch. Bilthoven: National Institute for Public Health and the Environment; 2009. [cited 2012 May 8]. Available from: http://www.rivm.nl/bibliotheek/rapporten/360050022.pdf.

17. Wendell JP, Schmee JP. Likelihood confidence intervals for proportions in finite populations. Am Stat. 2001;55:55-61.

18. Hollestelle ML, van Drongelen AW, Hilbers ESM, Stephan C, Boumans R. Medical devices intended for lay use in the EU. Regul Aff J Devices. 2009; 17:89-92.

19. Roszek B, van Drongelen AW, de Bruijn ACP, Geertsma RE. Assessment of technical documentation of medical devices for clinical investigation. Regul Aff J Devices. 2009;17:165-170.

20. ECRI. Top 10 health technology hazards for 2011. Health Devices. 2010;39:386-98.

21. Dutch Health Care Inspectorate IGZ. Chronische beademing vereist betere afstemming. Dutch. The Hague: IGZ; 2010. [cited year Month, day]. Available from: http://www.igz.nl/zoeken/document.aspx? doc $=$ Chronische_beademing_vereist_betere_afstemming\&URL.

22. Dutch Health Care Inspectorate IGZ. Staat van de gezondheidszorg 2004 - Patiëntveiligheid: de toepassing van geneesmiddelen en medische hulpmiddelen in zorginstellingen en thuis. Dutch. The Hague: IGZ; 2004. [cited 2012 May 8]. Available from: http://www.igz.nl/zoeken/ document.aspx?doc=Staat_van_de_Gezondheidszorg_2004\&URL.

23. FDA MedSun: HomeNet. [cited 2012 May 8]. Available from: http:// www.accessdata.fda.gov/scripts/cdrh/cfdocs/medsun/news/subnetworks. $\mathrm{cfm}$ ? subnet $=2$.

24. van Drongelen AW, Roszek B, van Tienhoven EA, et al. Annex II technical documentation assessed. Med Device Technol. 2005;16:21-3.

25. de Vries CGJCA, de Bruijn ACP, van Drongelen AW, Hilbers ESM, Roszek B, Geertsma RE. Point-of-care diagnostic devices. An assessment of safety related technical documentation items. Bilthoven: National Institute for Public Health and the Environment; 2010. [cited 2012 May 8]. Available from: http://www.rivm.nl/bibliotheek/rapporten/ 360050025.pdf. 